\title{
Effect of Brand Popularity in a Foreign Market on Consumer Behavior in a Franchise Cosmetic Retailer's Online Shop
}

\author{
Ji-Hern KIM" ${ }^{1}$, Tae Gyung GONG ${ }^{2}$, So Jung $\mathrm{AHN}^{3}$
}

Received: February 28, 2019 Revised: April 25, 2020 Accepted: April 30, 2020.

\begin{abstract}
Purpose: As consumers have difficulty in brand choice due to excessive information, using brand popularity as an advertising cue (e.g., Sales No. 1, Hit Product) has been getting more attention as an effective curation strategy for decreasing consumers' cognitive efforts. Accordingly, recent studies empirically demonstrate that consumers tend to prefer and choose a brand with a popularity cue and offer a useful information regarding how to use a popularity cue in marketing communication. However, extant research has mainly focused on investigating the impact of "brand popularity in a domestic market" on consumer behaviors. Thus, little is known about the effect of "brand popularity in a foreign market" on local consumers' decision-making process. Given that domestic consumers tend to purchase imported products from overseas countries, it can be meaningful information for global companies. Therefore, this research derives and tests the five hypotheses to examine how local consumers respond to brand popularity in a foreign market as an advertising cue. Specifically, it tests the three hypotheses regarding the direct and indirect effects of brand popularity in a foreign market on risk perception and purchase intention. Then, it tests two additional hypotheses about moderating effects of psychic distance on the relationship between brand popularity and risk perception as well as on the relationship between brand popularity and purchase intention. Seventy participants are exposed to an advertisement for an Indian cosmetic brand using a popularity cue in Indian market and answer the questions about brand evaluation. For data analysis, regression analysis is employed. The findings of this research show that perceived brand popularity lowers local consumers' perceived risk with a foreign brand. However, perceived brand popularity does not have a direct impact on purchase intention while it has an indirect effect through perceived risk. Meanwhile, psychic distance moderates the effect of perceived brand popularity on perceived risk level, but it has no impact on the relationship between brand popularity and purchase intention. This research is one of the first studies that demonstrate the positive impact of brand popularity in a foreign market on a local consumer's purchase decision, and it shows the effect can be moderated by psychic distance.
\end{abstract}

Keywords : Brand Popularity, Psychic Distance, Perceived Risk, Purchase Intention, Franchise Selection Shop

JEL Classification Code : L10, L2, L8

1 First Author, Associate Professor, School of Business, Sejong University, Seoul, South Korea. Email: jihern@sejong.ac.kr,

2 Co-Author Affiliation: Graduate student, School of Business, Sejong University, Seoul, South Korea, Email: changeworld51@gmail.com

3 Corresponding Author's Affiliation: Doctoral Candidate, School of Business, Sejong University, Seoul, South Korea, Email: Florence203175@gmail.com

(c) Copyright: Korean Distribution Science Association (KODISA)

This is an Open Access article distributed under the terms of the Creative Commons Attribution Non-Commercial License (https://creativecommons.org/licenses/by-nc/4.0/) which permits unrestricted non-commercial use, distribution, and reproduction in any medium, provided the original work is properly cited.

\section{1. 서론}

오늘날 소비자들은 정보 과부화(information overload) 문제로 심각한 선택 장애를 경험하고 있으며, 과거와 달리 지나치게 많아진 선택지는 소비자에게 선택의 즐거움을 주기보다 오히려 심리적 부담으로 작용하고 있다 (Hu \& Kishen, 2019). 따라서 최근 프랜차이즈 기업들은 소비자의 선택을 도와줄 수 있는 다양한 노력을 하고 있으며, 특히 
브랜드인기도(brand popularity)를 활용한 마케팅 커뮤니케이션 전략이 주목받고 있다 (Luan, Shan, Wang, \& Xiao, 2019).

히트상품, 베스트셀러, 판매량 1 위 등 특정 브랜드의 인기도를 보여주는 광고 단서에 노출될 경우, 소비자들은 이미 검증된 좋은 품질의 안전한 제품이라는 인식을 가질 수 있어 수많은 제품들 속에서 좀 더 쉬운 선택을 할 수 있는 장점이 있다. 따라서 소비자 행동 연구자들은 소비자의 선택을 도울 수 있는 브랜드인기도를 활용한 광고에 대한 소비자의 반응에 관심을 가져왔으나, 아직 프랜차이즈 기업들이 실무에서 효과적인 전략을 수립하기 위한 가이드라인을 제시하는 것은 미흡한 실정이다(Km, 2018; Dean, 1999).

특히 기존 연구들은 대부분 국내 시장에서의 브랜드인기도가 국내 소비자의 제품 평가에 미치는 효과에 초점을 두고 있다KKm \& Lee, 2008; Ryu, Park \& Park, 2006). 그러나 최근 온 오프라인 브랜드솝과 편집솝을 중심으로 국내 소비자가 해외제품을 구매하는 경우가 적지 않으며, 그 과정에서 국내 소비자는 해외 시장에서의 브랜드인기도를 활용한 광고에 쉽게 노출될 수 있다. 예를 들어, 국내 소비자가 미국 뷰티 프랜차이즈 기업(BODY \& WORKS)이 운영하는 온라인 매장에서 직접 구매를 하거나(이른바 직구), CJ 올리브영, LOHB's, 아리따움 등 국내 프랜차이즈 뷰티 매장(또는 온라인 쇼핑몰)을 방문하여 해외에서 수입된 화장품을 구매하고자 할 때 "미국시장 판매량 1 위"라는 광고단서에 노출될 수 있다. 물론 제품유형에 따른 차이는 있겠지만 미국시장이 한국시장보다 규모가 크기 때문에, 미국시장에서의 브랜드인기도가 한국시장에서의 브랜드인기도보다 판매량이 더 많았음을 의미할 수는 있겠으나 한국 소비자와 미국 소비자는 같은 제품이라 할지라도 서로 다른 평가기준을 가질 가능성이 있다.

이것은 프랜차이즈 기업들이 해외 시장에서의 브랜드인기도를 마케팅 커뮤니케이션에 활용할 때 국내 소비자들이 어떻게 반응할 것인지에 대한 심도 있는 이해가 필요함을 의미한다. 그러나 이와 관련 연구는 현재 매우 미흡한 실정이다. 예외적으로 Kim \& Min (2016)은 브랜드인기도 광고에 활용되는 해외국가의 소비자가 국내 소비자와 유사하고 해당 제품에 대한 전문성이 높은 경우, 해외국가에서의 브랜드인기도 단서가 국내 소비자의 구매의도에 보다 긍정적인 효과를 줄 수 있음을 보였다.

그러나 해외국가에서의 브랜드인기도의 단서가 국내 소비자의 구매의사결정에 중요한 역할을 할 수 있는 지각된 위험수준을 효과적으로 낮출 수 있는지에 대한 연구는 진행되지 않았다. 또한 기존 연구들을 통해 국내 시장에서의 브랜드인기도가 국내 소비자의 제품 품질 인식에 긍정적 효과를 미치며 지각된 위험 수준을 효과적으로 낮출 수 있음이 밝혀졌지만, 프랜차이즈 기업의 해외시장에서의 브랜드인기도가 국내 소비자의 지각된 위험에 미치는 효과는 확인되지 않았다(Km \& Min, 2014; Km \& Min, 2012). 뿐만 아니라 기존 연구는 글로벌 환경에서 국가 간 거래 시 중요하게 고려되는 변수들, 특히
심리적 거리감(psychic distance)이 해외시장에서의 브랜드인기도가 국내 소비자에 미치는 효과를 어떻게 조절할 수 있는지에 대해 관심을 갖지 않았다.

따라서 본 연구는 다음과 같은 두 가지 목적을 가지고 진행되었다. 첫째, 프랜차이즈 기업이 해외시장에서의 브랜드인기도를 마케팅 커뮤니케이션에 활용하여 국내 소비자의 지각된 위험 수준을 효과적으로 낮추고 구매의도를 증가시킬 수 있는지 알아보고자 한다. 둘째, 해외시장에서의 브랜드인기도가 국내 소비자의 지각된 위험과 구매의도에 미치는 효과를 심리적 거리감이 조절할 수 있는지 확인하고자 한다.

\section{2. 이론적 배경}

\section{1. 브랜드인기도의 결과변수: 지각된 위험수준과 구매의도}

브랜드인기도(brand popularity)는 얼마나 많은 소비자들이 특정 제품(또는 서비스)을 구매하고 소비하는지를 의미한다KKm \& Wang, 2018; Kim \& Chung, 1997). 온라인 쇼핑몰들은 "히트상품", "판매량 1 위" 등 다양한 유형의 브랜드인기도 단서를 광고에 활용 있으며, 기존 연구는 이러한 인기도의 단서들이 소비자의 온라인 구매행동에 미치는 효과가 긍정적임을 보여준다(Kim \& Min, 2014; Luan et al, 2019). 또한 "판매량 1 위"와 같이 좀 더 직접적으로 판매량 수준을 드러내는 광고 단서가 "히트상품"과 같이 추상적으로 인기도의 수준을 표현한 광고 단서에 비해 소비자들이 지각하는 인기도 수준이 높고, 구매의사결정에 더 긍정적인 영향을 미칠 수 있는 것으로 확인되었다(Km \& Min, 2012).

브랜드인기도에 관한 초기 연구들은 대부분 브랜드인기도가 소비자의 구매의사결정에 미치는 효과를 분석할 때 대리변수(proxy variable)로 시장점유율을 활용하였으며, 특히 시장점유율이 소비자가 지각하는 제품의 품질수준에 미치는 효과를 분석하였다. 그 결과 브랜드인기도가 긍정적인 영향을 미칠 것이라는 예상과 달리, 경우에 따라서 부정적 효과를 가질 수 있음이 확인되었다(Hellofs \& Jacobson, 1999). 예를 들면, 줄이 긴 레스토랑을 보면 음식이 맛있을 수 있겠다는 추정도 가능하지만 사람이 많아서 제대로 된 서비스를 받을 수 없겠다는 생각을 할 수도 있다. 그러나 한편으로 시장점유율이 높다는 것은 여러 소비자들에 의해 검증된 제품으로 품질 수준이 높다고 예측할 수도 있다. 따라서 시장점유율이 소비자의 구매의사결정 과정에 미치는 효과에 관한 연구들은 혼재된 결과(mixed result)를 보여준다.

그러나 우리는 이들 연구가 주로 오프라인 맥락에서 진행되었다는 사실에 주목할 필요가 있다. 온라인 쇼핑몰에서 사용하는 
브랜드인기도는 전체 시장의 점유율이 아닌 해당 쇼핑몰에서 판매되는 순위를 기준으로 결정되는 경우가 일반적이기 때문에(Kim \& Min, 2012), 오프라인에서 경험할지 모르는 시장점유율 증가에 따른 품질수준 하락 가능성이 매우 낮다. 따라서 기존 연구들은 온라인 쇼핑몰에서 브랜드인기도를 활용한 광고를 할 경우, 소비자의 지각된 품질 수준이 높아지고 위험수준은 낮아져 결과적으로 구매의도가 증가하는 것을 보였다Kim \& Min, 2014).

그러나 이들 연구는 주로 국내 소비자들이 국내에서의 브랜드인기도 단서에 어떻게 반응하는지를 분석하는데 초점을 두고 있다. 따라서 해외국가에서의 브랜드인기도 단서가 국내 소비자의 구매의사결정 과정에 긍정적으로 개입할 수 있는지 재확인할 필요가 있다. 국내에서의 브랜드인기도가 국내 소비자의 구매의사결정 과정에 미치는 효과에 관한 선행 연구결과들을 고려할 때 (Kim, 2018; Kim \& Wang, 2018), 해외국가에서의 브랜드인기도는 국내 소비자의 구매의도에 긍정적 효과를 가질 것으로 기대할 수 있다. 또한 온라인 쇼핑몰의 경우 오프라인에 비해 지각된 위험 수준이 구매의도에 미치는 효과가 큰 것으로 알려져 있다(Tucker \& Zhang, 2011). 따라서 해외에서의 브랜드인기도가 국내 소비자의 지각된 위험 수준을 효과적으로 낮춰 구매의도를 높이는 간접효과를 확인할 필요가 있다. 이를 토대로 다음과 같이 $\mathrm{H} 1, \mathrm{H} 2, \mathrm{H} 3$ 이 도출되었다.

H1: 해외국가에서의 브랜드인기도는 국내 소비자의 지각된 위험수준을 낮출 것이다.

H2: 해외국가에서의 브랜드인기도는 국내 소비자의 구매의도를 높일 것이다.

H3: 지각된 위험 수준은 국내 소비자의 구매의도에 미치는 효과를 낮출 것이다.

\section{2. 브랜드인기도 효과의 조절변수: 심리적 거리감}

심리적 거리(psychic distance)라는 용어는 Beckeman(1956)이 국제무역의 확산에 관한 연구에서 처음 소개한 이후 다국적기업의 국제화 전략과 해외 자회사의 조직성과에 관한 다양한 학자들의 연구에 사용되면서 그 의미가 점차 변화되어 왔다(Safari \& Chetty, 2019).

초기의 연구에서는 심리적 거리가 공급자와 구매자 사이의 정보의 흐름을 방해하는 요인들로 정의되었으며, 이후 기업이 해외시장에 진출하고자 할 때 외국시장에 대한 이해와 학습을 방해하는 요인들로 정의됨으로써 다국적 기업의 전략적 고려요인으로 좀 더 구체화되었다(Nordstrom \& Vahlne, 1994).

1990 년대 후반에 들어서면서, 심리적 거리는 외국시장에서 기업을 운영하고 시장환경을 학습하는데 있어 방해가 되는 문화적 차이에서
발생되는 외국시장에 대한 불확실성의 정도로 정의되었다(O'Grady \& Lane, 1996). 그러나 2000 년대에 접어들면서 불확실성(uncertainty)과 거리(distance)는 명확히 다른 개념임에도 불구하고 혼용되어 사용하는 문제점이 제기되었다(Evans, Treadgold \& Manondo, 2000). 즉, 거리는 두 대상 간의 분리된 정도를 의미하는 것으로 유사함과 다름의 정도를 의미하는 반면, 불확실성은 지식의 부족으로 대상에 대해 잘 알지 못하는 것을 의미한다. 또한 심리적(psychic)이라는 용어가 마음(mind) 또는 정신(soul)이라는 개념을 내포하고 있다는 측면에서 심리적 거리를 판단할 때는 시장 환경의 차이가 아닌 개인적 인식의 차이를 평가해야 한다는 주장이 대두하였다(Evans \& Mavondo, 2002).

따라서 이를 종합하면 심리적 거리는 "외국과 자국이 얼마나 유사한지에 대한 개인적 인식의 차이"로 정의될 수 있다. 이에 따라 심리적 거리를 측정하기 위해 문화적 가치와 믿음, 교육수준, 라이프스타일, 언어, 소비자 선호도, 제품 구매력 등에 관한 다양한 차원에서 개별 응답자가 인지하는 국가 간 차이를 평가하고 있다Safan \& Chetty, 2019; Sousa \& Bradley, 2006; Hwang, 2009). 정보 발신자의 유사성 효과(source similanity effect)에 따르면 정보 수신인은 자신과 유사한 발신인의 주장에 더 잘 설득될 수 있다(lbok, 2013; Erdogan, 1999). 이는 소비자가 해외 브랜드 국가에 대한 심리적 거리를 가깝게 인식할 경우, 브랜드인기도를 활용한 광고에 대한 반응이 더 긍정적일 수 있음을 의미한다. 즉, 브랜드인기도의 광고가 효과적으로 소비자의 지각된 위험수준을 낮추고 구매의도를 증가시킬 것으로 예측해 볼 수 있다. 이를 근거로 다음과 같이 $\mathrm{H} 4$ 와 $\mathrm{H} 5$ 를 도출하였다.

H4: 국내 소비자가 브랜드인기도를 주장하는 해외국가와의 심리적 거리감이 가까울수록 브랜드인기도가 지각된 위험수준에 미치는 부정적 효과가 클 것이다.

H5: 국내 소비자가 브랜드인기도를 주장하는 해외국가와의 심리적 거리감이 가까울수록 브랜드인기도가 구매의도에 미치는 긍정적 효과가 클 것이다.

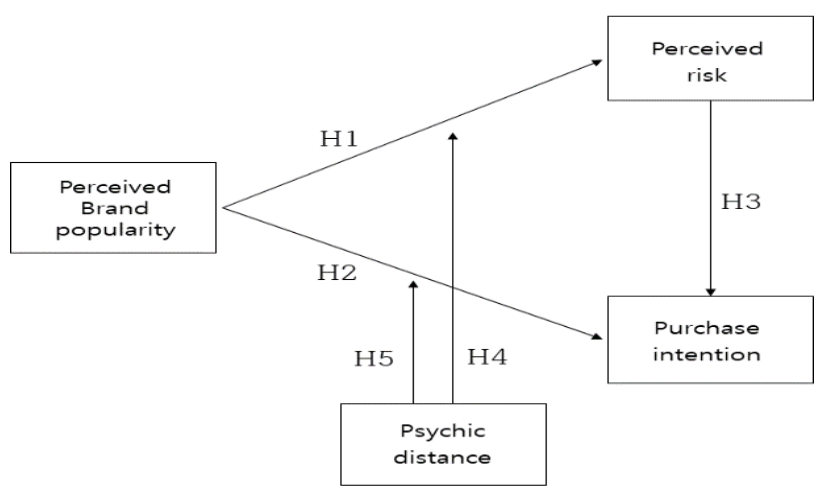

Figure 1: Conceptual Framework 


\section{3. 연구조사}

\section{1. 조사방법}

서울시내에 위치한 대학의 학부생 70 명(남자: 29 명, 여자: 41 명)이 설문조사에 참가하였다. 국내에 해외 수입 화장품을 온오프라인으로 판매하고 있는 프랜차이즈 뷰티 편집숍들(예, $\mathrm{CJ}$ 올리브영)이 매우 다양하며 실험참가자인 대학생들에게 매우 익숙하므로 글로벌 화장품 브랜드를 본 연구의 실험자극(experimental stimulus)으로 선택한 후 광고물을 제작하였다.

구체적으로 인도의 화장품 브랜드인 "히말라야(-Himalaya)"의 핸드크림에 대한 광고물을 "인도시장 판매량 1 위"라는 인기도 단서를 활용한 것과 그렇지 않은 것으로 각각 제작한 후 이를 토대로 구매 시나리오를 개발하였다. 조사 참가자들은 추워진 겨울 날씨 때문에 건조해진 손등에 바를 핸드크림을 구매하기로 결정한 후 온라인 쇼핑을 하던 중 히말라야 광고에 노출되었다고 생각하도록 요청을 받았다. 설문에 제시된 광고물은 Kim and Min (2016)의 연구에 사용된 동일한 광고물이 사용되다. 먼저 참가자들을 광고물에 노출시킨 후 "광고에서 보신 히말라야 핸드크림의 인도 판매량은 어느 정도일 것이라 생각되십니까"라는 7 점 척도(1 점: 전혀 판매되지 않았다, 7점: 매우 많이 판매되었다)의 단일항목을 이용해 지각된 브랜드인기도를 측정하였다.

인도국가에 대한 심리적 거리(psychic distance)는 6 개 항목(라이프스타일, 문화적 가치 및 신념, 구매력, 제품선호도, 교육수준, 언어 친근감)으로 측정되었다 $(\alpha=0.769)$.

지각된 위험수준은 Jacoby and Kaplan (1972)의 연구를 참조하여 총 6 개 문항으로 측정되었대 $(\alpha=0.914)$. 구체적으로 화장품 제품과 관련성이 높다고 판단되는 2 가지 유형의 위험, 즉 성능적 위험(performance risk)에 관한 3 개 문항과 신체적 위험(physical nisk)에 관한 3 개 문항을 활용하였다. 구매의도는 Gill, Grossbart and Lacniak (1988)에서 사용한 문항을 토대로 "핸드크림을 구매하기로 결정하였다면 광고에서 본 히말라야 핸드크림을 구매할 가능성은 얼마입니까"라는 질문에 대한 7점 척도의 4 개 문항(전혀 가능성 없음반드시 구매, 매우 확률이 낮음 매우 확률이 높음, 전혀 불가능-매우 가능성이 높음, 매우 현실성 없음 매우 현실적 $)$ 으로 측정되었다 $(\alpha=0.925)$. 마지막으로 성별, 나이, 국적에 관한 인구통계학적 문항이 포함되었다.

\section{4. 분석결과}

브랜드인기도침리적 거리를 독립변수로, 지각된 위험 수준을 종속변수로 하는 회귀분석(regression)이 실시되었다. 분석 결과, 지각된
위험에 미치는 브랜드인기도의 주 효과와 브랜드인기도와 심리적 거리의 상호작용효과가 유의한 것으로 나타났다 $\left(R^{2}=0186\right)$. 따라서 $\mathrm{H} 1$ 와 $\mathrm{H}$ 4는 지지되었다(Appendix 1 Refer).

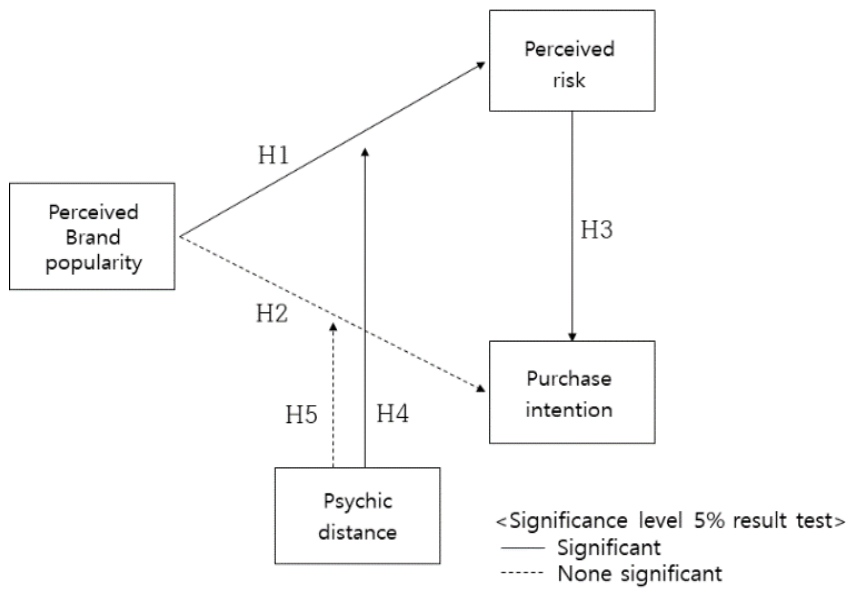

Figure 2: Analysis Result Framework

다음으로 $\mathrm{H} 2, \mathrm{H} 3, \mathrm{H} 5$ 를 검정하기 위해, 브랜드인기도, 심리적 거리, 브랜드인기도심리적 거리, 지각된 위험을 독립변수로, 구매의도를 종속변수로 하는 회귀분석이 실시되었다 $\left(\mathrm{R}^{2}=0.308\right)$ 분석결과 위험수준이 구매의도에 미치는 효과가 유의하게 나타나 $\mathrm{H3}$ 은 지지되었으나, 브랜드인기도가 구매의도에 미치는 주효과와 브랜드인기도와 심리적 거리가 구매의도에 미치는 상호작용 효과가 유의하지 않아 H2 와 H5 는 기각되었다(Appendix 2 Refer). H2 와 H5 가 기각된 것은 브랜드인기도와 심리적 거리가 구매의도에 미치는 직접적 효과는 없으며 지각된 위험수준에 영향을 줌으로써 간접적인 영향만 줄 수 있음을 의미한다.

\section{5. 결론}

\section{1. 연구결과의 요약 및 시사점}

본 연구는 국내 소비자들이 프랜차이즈 기업들이 판매하는 해외 브랜드에 대한 인기도 광고 단서에 어떻게 반응하는지를 분석한 것으로 다음과 같은 시사점이 있다. 먼저 본 연구는 대부분의 기존 연구가 국내 소비자의 국내시장에서의 브랜드인기도를 이용한 광고단서에 어떻게 반응하는지를 살펴본 것과 달리 그 범위를 해외 브랜드로 확장하였다는 점에 의의가 있다. 특히 국내 소비자가 프랜차이즈 기업의 온라인쇼핑몰에서 해외 브랜드를 구매할 때 구매의사결정 과정에 큰 영향을 미칠 수 있는 지각된 위험수준을 연구모형에 포함시켜 
브랜드인기도를 활용하여 구매의도를 높일 수 있는 기저원리(underlying medhanism)를 분석했다는 점에 의의가 있다.

한편 최근 프랜차이즈의 글로벌화(intemational franchising)에 대한 연구가 크게 주목받고 있으며 특히 해외시장 진출과 관련된 파트너십과 운영방식에 영향을 줄 수 있는 핵심요인들을 밝히고자 노력하고 있다 (Rosado-Serrano, Paul, \& Dikova, 2018). 그러나 글로벌 기업들이 해외 프랜차이즈 유통매장을 이용하여 현지 소비자들에게 효과적으로 커뮤니케이션 할 수 있는 방법에 대한 연구는 찾아보기 어렵다. 따라서 본 연구는 프랜차이즈 기업이 직접 해외로 진출하는 전략에 초점을 맞춘 기존 연구들과 달리 글로벌 기업이 매출 증대를 위해 현지 프랜차이즈 기업들과 협력하여 효과적인 마케팅 커뮤니케이션 전략을 수립하는데 필요한 정보를 제공한다는 점에 차별점이 있다.

본 연구의 또 다른 이론적 시사점은 기존 브랜드인기도 연구에서 고려하지 않았던 국내 소비자가 해외 국가에 대해 가지는 심리적 거리를 브랜드인기도 효과의 조절변수로 고려하였다는 점이다. 비록 기존 연구에서 해외 국가에 대한 국내 소비자의 부정적 감정, 즉 적대감(animosity)을 브랜드인기도의 조절변수로 고려하긴 하였지만(Km \& Wang, 2018; Kim \& Min, 2016), 심리적 거리와 같은 중립적 성격의 변수를 고려하지 않았다. 심리적 거리가 국제 마케팅(intemational marketing) 분야의 연구에서 오랫동안 중요한 변수로 고려되어 왔다는 점에서, 향후 브랜드인기도와 이들 연구들의 접점을 만들어 갈 수 있는 계기를 제공하였다는 점에 의의가 있다.

본 연구의 결과는 실무적으로도 의미를 가진다. 특히 오늘날 블랙 프라이데이와 크리스마스 시즌을 중심으로 국내 소비자들의 해외 브랜드 구매가 늘어가고 있으며, 반대로 국내 온라인 쇼핑몰의 판매 범위가 해외 소비자까지 확대되고 있다. 따라서 본 연구는 글로벌 쇼핑환경에서 글로벌 제조업체들뿐 아니라 현지 프랜차이즈 기업들이 브랜드인기도를 광고단서로 활용할 수 있는 전략적 방향성을 제시한다는데 의의가 있다. 특히 심리적 거리가 멀지 않은 국가의 소비자들을 중심으로 해외시장에서의 브랜드인기도를 광고단서로 보다 적극적으로 활용해야 함을 말해준다.

\section{2. 연구의 한계 및 향후 연구 방향}

본 연구는 앞서 언급한 이론적, 실무적 시사점에도 불구하고 다음과 같은 몇 가지 한계가 있으며 향후 연구에서는 이를 보완할 필요가 있다. 첫째, 본 연구는 해외시장에서의 브랜드인기도에 대한 국내 소비자의 반응만을 분석하였다. 현지 프랜차이즈 기업을 통해 해외 진출을 계획하는 국내 글로벌 제조기업들을 위한 전략적 시사점을 제공하기 위해서는 해외 소비자들이 국내시장에서의 브랜드인기도 단서에 어떻게 반응하는지를 분석할 필요가 있다. 이는 해외 소비자들의
국적에 따른 차이도 매우 클 것으로 보이므로, 향후 다양한 국적의 소비자를 샘플로 하는 연구가 진행될 필요가 있음을 의미한다.

둘째, 브랜드인기도 단서로 "판매량 1 위"만 사용하였다는 한계가 있다. 기존 연구결과에 따르면, 인기도 단서의 유형에 따라 소비자의 반응에는 차이가 있을 수 있다. 예를 들어, 판매량 1 위와 달리 히트상품이나 인기상품과 같이 구체적으로 판매량을 언급하지 않은 경우, 소비자의 구매의사결정에 미치는 영향이 상대적으로 낮게 나타났다 (KM \& Min, 2012). 따라서 향후 연구에서는 다양한 브랜드인기도 단서를 사용하는 경우에도 동일한 결과를 얻을 수 있는지 확인할 필요가 있다.

마지막으로, 제한된 실험 자극(stimulus product), 실험참가자와 가상의 시나리오를 적용한 연구로 결과를 일반화하는 데에는 주의가 필요하다. 본 연구는 시나리오를 제시하는 설문을 통해 인도시장에서의 핸드크림 브랜드(즉, 히말라야)의 인기도에 대한 국내 대학생들의 반응을 연구하였다. 화장품으로 유명한 인도가 아닌 다른 국가예, 일본, 프랑스)의 경우, 핸드크림과 같은 저관여 제품이 아닌 고관여 제품인 경우, 대학생이 아닌 다른 인구통계적 특성을 가지는 집단의 경우에는 본 연구의 결과와 다른 결과를 얻을 가능성이 있다. 따라서 향후 연구에서는 여러 조건들을 변경한 반복 연구를 통해 이러한 외적타당성(extemal validity)의 문제를 보완할 필요가 있다.

\section{References}

Beckerman, W. (1956). Distance and the pattern of intraeuropean European trade. The Review of Economics and Statistics, 38(1), 31-40.

Dean, D. H. (1999). Brand endorsement, popularity, and event sponsorship as advertising cues affecting consumer prepurchase attitudes. Journal of Advertising, 28(3), 1-12.

Erdogan, B. Z. (1999). Celebrity endorsement: A literature review. Journal of Marketing Management, 15(4), 291-314.

Evans, J., \& Mavondo, F. T. (2002). Psychic distance: The construct and measures. Paper Presented at American Marketing Association Conference Proceedings, Chicago,American Marketing Association, 13(Summer), 308314.

Evans, J., Treadgold, A., \& Mavondo, F. (2000). Explaining export development through psychic distance. International Marketing Review, 17(2), 164-168.

Gill, J. D., Gorssbart, S., \& Laczniak, R. N. (1988). Influence of involvement, commitment and familiarity on brand beliefs and attitudes of viewers exposed to alternative ad claim strategies. Journal of Advertising, 17(2), 33-43.

Hellofs, L. L., \& Jacobson, R. (1999). Market share and customers' perception of quality: When can firms grow their way to higher versus lower quality? Journal of Marketing, 63(1), 16-25.

$\mathrm{Hu}, \mathrm{H}$., \& Krishen, A. S. (2019). When is enough? Investigating product reviews and information overload from a consumer 
empowerment perspective. Journal of Business Research, 100, 27-37.

Hwang, H.C. (2009). The effect of perceived risks and performance regarding psychic distance. Journal of Distribution Science, 7(2), 63-88

Ibok, N. I. (2013). Factors determining the effectiveness of celebrity endorsed advertisements: the The case of Nnigerian telecommunication industry. American Journal of Business and Management, 2(3), 233-238.

Jacoby, J., \& Kaplan, L. (1972). The components of perceived risk. The Advances in ssociation for Consumer Reasearch, 3, 382393

Kim, C. K., \& Chung, J. Y. (1997). Brand popularity, country image and market share: an empirical study. Journal of International Business Studies, 28(2), 361-386.

Kim, J. H., \& Min, D. W. (2014). The effects of brand popularity as an advertising cue on perceived quality in the context of Internet. Japanese Psychological Research, 56(4), 309-319.

Kim, J. H., \& Min, D. W. (2012). The effects of product brand popularity on quality perception and purchase intention in the context of internet shopping. Journal of Consumption Culture 15(4), 25-41.

Kim, J. H., \& Min, D. W. (2016). Consumers' response to an advertisement using brand popularity in a foreign market. Japanese Psychological Research, 58(4), 342-354.

Kim J. H. (2018). Effect of brand popularity as an advertising cue on tourists' shopping behavior. Journal of Destination Marketing \& Management 10, 78-86.

Kim, J. H., \& Wang, L. L. (2018). Effect of brand popularity on purchase intention in the context of tourist shopping: Moderating effects of situational involvement and animosity. Journal of Industrial Economical \& Trade, 42(1), 35-53.
Lee, T. M., \& Kim, D. W. (2008). Consumers' cognitive, affective and behavioral responses to hit product awards as extrinsic cue: The moderating role of product involvement and product type. Korean Journal of Marketing, 23(4), 71-103.

Luan, J., Shan, W., Wang, Y., \& Xiao, J. (2019). How easy-toprocess information influences consumers over time: Online review vs. brand popularity. Computers in Human Behavior, 97 , 193-201

Nordstrom, K., \& Vahlne, J. E. (1994). Is the globe shrinking? Psychic distance and the establishment of Swedish sales subsidiaries during the last 100 years. Chapter in International Trade: Regional and global Issues, M. Landeck, ed. United Sates : St. 41-56.

O'grady, S., \& Lane, H.W. (1996). The psychic distance paradox. Journal of International Business Studies, 27(2), 309-33.

Rosado-Serrano, A., Paul, J., \& Dikova, D. (2018). International franchising: A literature review and research agenda. Journal of Business Research, 85, 238-257.

Ryu, G. S., Park, J. C., \& Park, C. S. (2006). Consumer responses toward hit product awards: The moderating role of product knowledge and brand strength. Korean Journal of Marketing, 21(1), 57-80.

Safari, A., \& Chetty, S. (2019). Multilevel psychic distance and its impact on SME internationalization. International Business Review, 28(4), 754-765

Sousa, C. M. P., \& Bradley, F. (2006). Cultural distance and psychic distance: two peas in a pod? Journal of International Marketing, 14(1), 49-70.

Tucker, C., \& Zhang, J. (2011). How does popularity information affect choices? A field experiment. Management Science, 57(5), $828-842$. 